\title{
Analysis of iron-containing compounds in different compartments of the rat liver after iron loading
}

\author{
Patricia L. Ringeling ${ }^{1}$, Maud I. Cleton ${ }^{1}$, Marja I. E. Huijskes-Heins ${ }^{1}$, Marionne J. E. Seip ${ }^{1}$, \\ Wim C. de Bruijn², and Henk G. van Eijk ${ }^{1}$ \\ Departments of ${ }^{1}$ Chemical Pathology and ${ }^{2}$ Pathological Atonomy, AEM Unit, Erasmus University Rotterdam, P. O. Box 1738 , \\ NL-3000 DR Rotterdam, The Netherlands
}

Received June 3, 1990

\begin{abstract}
Summary. The livers of iron-loaded rats were fractionated and a cytosolic fraction, a lysosomal fraction, a siderosomal fraction and haemosiderin were obtained. All iron-containing compounds from these fractions were isolated and their morphology, $\mathrm{Fe} / \mathrm{P}$ ratios, iron core diameter and peptide content were compared. The cytosolic fraction contained ferritin (CF) and a slower sedimenting, light ferritin (CLF). The lysosomal fraction also contained ferritin (LF) and a slower sedimenting light ferritin (LLF). The siderosomal fraction contained ferritin (SF), a faster sedimenting non-ferritin iron compound (SIC) and haemosiderin (HS). SIC and HS did not resemble ferritin as much as the other products did, but were found to be water-insoluble aggregates. The $\mathrm{Fe} / \mathrm{P}$ ratios of $\mathrm{CF}$ and $\mathrm{CLF}$ were lower than the $\mathrm{Fe} / \mathrm{P}$ ratios of $\mathrm{LF}$ and LLF and these in turn had lower $\mathrm{Fe} / \mathrm{P}$ ratios than $\mathrm{SF}, \mathrm{SIC}$ and $\mathrm{HS}$. The iron core diameter of the cytosolic ferritin was increased after lysosomal uptake. The iron core diameters of the siderosomal products were smaller. CLF, CF, LF, LLF and SF contained one kind of subunit of approximately 20.5 $\mathrm{kDa}$. SIC and HS contained other peptides in addition to the $20.5-\mathrm{kDa}$ subunit. The results indicate that storage of ferritin molecules is not limited to the cytosolic compartment, but is also the case in the lysosomes. Extensive degradation of the ferritin molecule seems to be confined to the siderosomes.
\end{abstract}

Key words: Electron spectroscopy - Ferritin - Haemosiderin - Iron-loaded rat - Morphometry

\section{Introduction}

One of the main characteristics of haemochromatosis is the presence of vast amounts of iron in liver, spleen and heart in the form of ferritin and haemosiderin (Richter 1978; Iancu et al. 1978; Sindram and Cleton 1986;

Offprint requests to: $\mathrm{P}$. L. Ringeling
Theil 1987). Both compounds contain an iron-oxyhydroxide-phosphate core in which a variable amount of iron is stored (Harrison et al. 1987). In ferritin the core is surrounded by a protein shell consisting of 24 polypeptide subunits that keeps the iron in a soluble form. In contrast to ferritin, haemosiderin is water-insoluble, probably due to the lack of parts of the protein shell (Weir et al. 1984). Another morphological difference is that haemosiderin cores are more irregular and smaller than ferritin cores (Wixom et al. 1980). It is generally assumed that haemosiderin is derived from ferritin as their iron cores have similar X-ray diffraction patterns (Fischbach et al. 1971) and their shells share peptides (Weir et al. 1984). The most likely site for the degeneration of ferritin into haemosiderin is the lysosomes, because lysosomes contain the enzymes for protein breakdown (De Duve and Wattiaux 1966) and it is the only place where ferritin and haemosiderin exist side by side. On the other hand, a lysosomal enzyme suitable for the digestion of ferritin has still not been found (Richter 1986; Hultcrantz et al. 1984). To investigate a possible transition process various studies of haemosiderin and ferritin have been performed in an ironloaded rat model, such as Mössbauer spectra (Rimbert et al. 1985), iron release and uptake (Harrison et al. 1974; Brady et al. 1989; Biemond et al. 1984), the iron core composition and diameter (Treffry et al. 1987; Andrews et al. 1988a) and peptide content (Weir et al. 1984; Andrews et al. 1987). Yet it is still not entirely clear how and where a possible transition takes place (Hoy and Jacobs 1981; Richter 1986; Cooper et al. 1988).

Our previous chromatographic studies (Ringeling et al. 1989) in iron dextran-treated rats have shown that the diameter and the $\mathrm{Fe} / \mathrm{P}$ mass ratios of the main cytosolic ferritin fraction were smaller compared to the diameter and the $\mathrm{Fe} / \mathrm{P}$ ratios in the main siderosomal ferritin fraction. Moreover, $\mathrm{Fe} / \mathrm{P}$ ratios of these ferritins could not be changed significantly by extensive dialysis. In this study, we fractionated the livers of similarly treated rats based on the fractionation scheme of Richter (1984). This allowed us to isolate, besides hae- 
mosiderin, a cytosolic fraction, a lysosomal fraction and a siderosomal fraction in one procedure. From these fractions we isolated all iron-containing products. By comparing their iron and protein characteristics, we followed the processing of cytosolic ferritin in lysosomes and siderosomes.

\section{Materials and methods}

Animals. Iron-loaded male Wistar rats weighing 300-320 $\mathrm{g}(n=12)$ were obtained by giving four intraperitoneal injections of Imferon (Fisons, UK) in a total dose of $100 \mathrm{mg} \mathrm{Fe}$ (III) spread over a period of four weeks. After the last injection the rats received no further treatment for a period of four weeks (resting period). Immediately after the resting period, the livers were processed.

Fractionation of the liver and isolation of iron-containing compounds. Rats were anesthetized intraperitoneally with $0.7 \mathrm{ml}$ pentobarbital $(35 \mathrm{mg})$. The blood of the liver was washed out by a brief perfusion through the portal vein with $0.15 \mathrm{M} \mathrm{NaCl}$, flow $20-25 \mathrm{ml} / \mathrm{min}$. The liver was removed, frozen in liquid $\mathrm{N}_{2}$ and stored at $-20^{\circ} \mathrm{C}$ until fractionation. For additional experiments fresh livers were used. Fractionation was performed based on the method of Richter (1984), see Fig. 1. Briefly, the homogenate, prepared in $0.3 \mathrm{M}$ sucrose, was spun down twice yielding a supernatant, representing the (ferritin-containing) cytosolic fraction, and a pellet. This pellet was layered on a discontinuous sucrose gradient (1.4-2.2 M) yielding a pellet (the heavy lysosomes=siderosomes) and several bands, including the lighter lysosomes. Bands at least 1.5 times enriched in lysosomal arylsulphatase activity (EC 3.1.6.1; Milsom et al. 1972) were pooled. Both pellet and pooled bands yielded, after ultrasonic treatment and centrifugation, a pellet in which the haemosiderin was found and a superna-

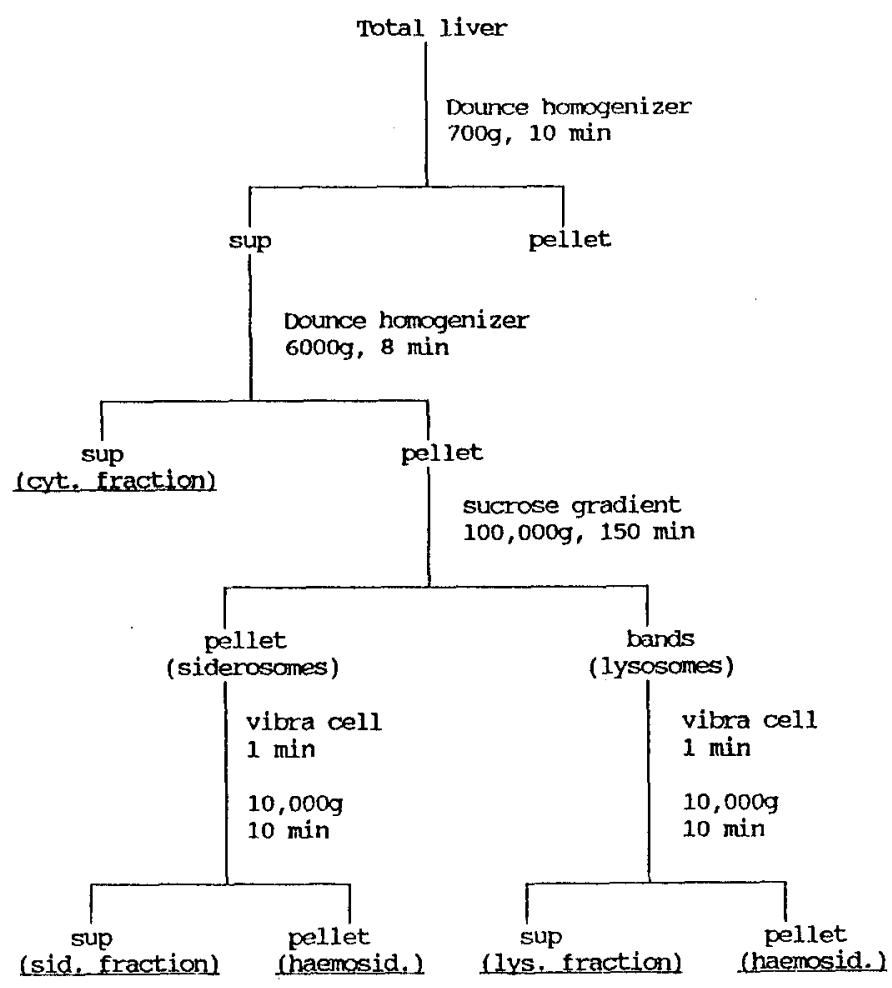

Fig. 1. Fractionation scheme for the preparation of the cytosolic, lysosomal and siderosomal fraction and the haemosiderin-containing fraction

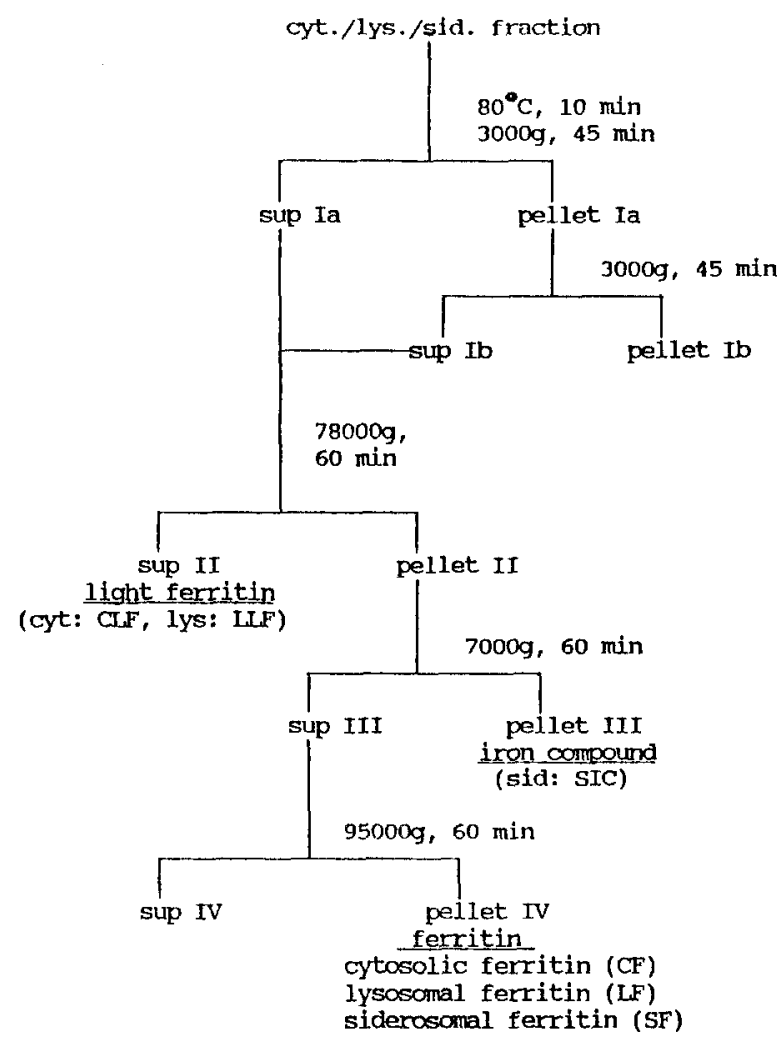

Fig. 2. Ferritin isolation scheme according to Penders et al. (1968)

tant, representing the (ferritin-containing) siderosomal and lysosomal fraction, respectively (Fig. 1). The haemosiderin from the siderosomes was further processed as described before (Ringeling et al. 1989), lyophilized and solubilized in $20 \mathrm{mM}$ tetramethylammonium hydroxide (Weir et al. 1984). The haemosiderin yield from the lysosomes was too low to be analysed. Subsequently, the three ferritin containing fractions mentioned before (cytosolic, lysosomal and siderosomal) were processed using $0.15 \mathrm{M} \mathrm{NaCl} \mathrm{ac-}$ cording to the procedure of Penders et al. (1968), see Fig. 2. In this procedure, we screened all intermediate and end products from this isolation scheme for the presence of iron-containing compounds. Water-soluble products were taken up in $0.15 \mathrm{M} \mathrm{NaCl}$ and water-insoluble compounds were solubilized in $20 \mathrm{mM}$ tetramethylammonium hydroxide.

Immunoreactivity. Each intermediate and end product of the above-mentioned procedure was reacted with rabbit anti-(rat liver ferritin) antiserum (Mostert et al. 1989) in an Ouchterlony immunodiffusion assay.

Determination of iron and protein. In all products iron concentration was determined according to the method of Harris (1978). Absorbance was measured at $562 \mathrm{~nm}$. Ferritin protein was determined by radial immunodiffusion as described by Mancini et al. (1965) with rabbit anti-(rat liver ferritin) antiserum (Mostert et al. 1989).

Electron microscopy. All products were air-dried on carbon-coated Formvar ${ }^{\mathrm{R}}$-filmed copper grids and examined in a Zeiss EM 902 transmission electron microscope. This instrument is equipped with an integrated electron energy spectrometer allowing, with energy-filtered (in our case zero loss) monospecific electrons, highresolution contrast imaging (electron spectroscopic imaging, ESI) and element-specific imaging (electron energy loss spectroscopy, EELS) (Ottensmeyer and Andrew 1980). In addition to using the 
EELS imaging mode, it is possible to acquire EELS spectra, comprised of element-specific edges, over a continuum representing electrons which have suffered aspecific energy losses. In our case, iron was identified in the EELS spectrum by two Fe-specific peaks at $\Delta E=710-730 \mathrm{eV}$. For further details see Hezel and Bauer (1987) and Cleton et al. (1989). Calculations of core diameters were accomplished by computer-assisted ESI image processing with the aid of an Ibas/Kontron 2000 (Mostert et al. 1989; Cleton et al. 1989). Approximately 500-1000 iron cores per ferritin fraction were measured for particle size distribution. Diameters of particles of non-ferritin compounds were measured by hand from the ESI micrographs.

Determinations of Fe/P ratios by EPMA. Aliquots $(5 \mu \mathrm{l})$ of each of the samples, comprising ferritins and solubilized non-ferritin compounds, were dried on carbon-coated Formvar ${ }^{R}$-filmed grids and analysed in a Philips EM 400 analytical electron microscope, operating at $80 \mathrm{kV}$ from a $\mathrm{LaB}_{6}$ electron source and equipped with a Tracor Northern, type TN2000, X-ray microanalyser. Multiple point analyses were performed at random over the grid squares essentially as described by Cleton et al. (1986). Peaks in the recorded spectra were identified by the available peak identification program. Net-intensity values for iron and phosphorus were obtained by the introduction of $400-\mathrm{eV}$-wide regions around the identified peaks and calculation by the energy filter program of the TN2000 computer software.

Gel electrophoresis and Western blotting. Non-denaturing polyacrylamide gel electrophoresis (PAGE) was carried out in 5\% gels using Tris/glycine $\mathrm{pH} 8.3$ or in Pharmacia precast gradient gels $2 / 16$ following manufacturer's instructions, in a Pharmacia GE $2 / 4$ chamber. Gels were stained for protein with Coomassie brilliant blue G-250 and for iron with $2 \% \mathrm{~K}_{4} \mathrm{Fe}(\mathrm{CN})_{6}$ in $2 \% \mathrm{HCl}$. Ferritins, non-ferritin compounds and markers (Pharmacia HMW kit) were dissociated into subunits by heating $\left(100^{\circ} \mathrm{C}, 5-10 \mathrm{~min}\right)$ in the presence of $2 \%$ (mass $/$ vol.) SDS and $20 \mathrm{mM}$ dithiothreitol just before electrophoresis. SDS/PAGE was carried out in $15 \%$ polyacrylamide gels using the Laemmli buffer system (Laemmli 1970) or in Pharmacia precast gradient gels $2 / 16$. Gels were stained for protein with Coomassie brilliant blue G-250. For blotting, SDS/ PAGE was carried out in $18 \%$ gels in a Bio-Rad Mini Protean II cell followed by electrophoretic transfer blotting in a Bio-Rad Mini Trans Blot cell. Proteins were stained with amido black, or blocked with gelatin and subsequently incubated with rabbit anti(rat liver ferritin) antibody (Mostert et al. 1989) overnight. This was followed by washing and incubation with alkaline-phosphatase-conjugated goat anti-rabbit IgG (Bio-Rad). Immunostaining was performed according to the manufacturer's instructions.

\section{Results}

\section{Iron compounds}

From the cytosolic fraction two iron-containing products were isolated, one 'normal' ferritin end product (CF) and a intermediate product in the $78000 \mathrm{~g}$ supernatant (Fig. 2, sup II). A similar result was obtained for the lysosomal fraction: a ferritin end product (LF) and an intermediate product in the $78000 \mathrm{~g}$ supernatant (Fig. 2, sup II). The siderosomal fraction also yielded two products: the 'normal' ferritin end product (SF) and an intermediate product in the $7000 \mathrm{~g}$ pellet (Fig. 2, pellet III). In addition to the haemosiderin (HS) isolated earlier (Fig. 1), the end products and the intermediate products were tested in an Ouchterlony assay to determine their reaction with anti-(rat liver ferritin).
Except for the haemosiderin and the intermediate product from the siderosomes, they all reacted with the antibody. Based on their positive reaction with specific antiserum we called the cytosolic intermediate product cytosolic light ferritin (CLF) and the lysosomal intermediate product lysosomal light ferritin (LLF). The siderosomal intermediate product was called siderosomal iron component (SIC). From CLF and LLF lowmolecular-mass material was isolated by means of centrifugation at $95000 \mathrm{~g}$. The material was found in the supernatant, proved to be ferritin-related (see Fig. 6) and will be subject to further study.

\section{Morphology}

All products reacting with the anti-(rat liver ferritin) serum morphologically resembled ferritin: round particles lying in paracrystalline arrays as shown in the ESI micrographs of Fig. 3. The SIC, which indeed contained iron as shown by the EELS spectrum (Fig. 4), morphologically resembled haemosiderin (Fig. 3). Core size determination of ferritins is presented in Table 1 .

\section{Fe $/ P$ ratios}

The $\mathrm{Fe} / \mathrm{P}$ mass ratios of the ferritins, the SIC and the haemosiderin as determined by EPMA are presented in Table 1.

\section{Iron determination}

The amount of material available was just enough to calculate once only the number of iron atoms/ferritin molecule, indicating an iron-richer core in the lysosomal ferritins than in the cytosolic ferritins. Siderosomal ferritin-iron content could not be determined.

\section{Protein analysis}

On a $5 \%$ polyacrylamide gel CF, CLF, LF, LLF and SF each showed one band with the same migration rate staining positively for protein and iron. The material removed from CLF and LLF also showed one band, but this band migrated much faster and stained positively for protein but negative for iron. HS and SIC did not migrate at all.

On a $15 \%$ SDS gel CF, CLF, LF, LLF, SF, SIC and HS showed a band at $20.5 \mathrm{kDa}$. In addition to this band SIC and (sometimes) HS also showed several bands in the region of $60-67 \mathrm{kDa}$ and a band at $36 \mathrm{kDa}$. HS (always) showed an extra band at $14 \mathrm{kDa}$ (Fig. 5). The fast migrating material from CLF and LLF showed one band at $14.4 \mathrm{kDa}$ (not shown).

The 20.5-kDa bands of CF, CLF, LF and LLF and the $14.4-\mathrm{kDa}$ band of the fast migrating material from CLF and LLF were positive in the Western blot (Fig. 6). In the Western blot the $20.5-\mathrm{kDa}$ subunit was found at 


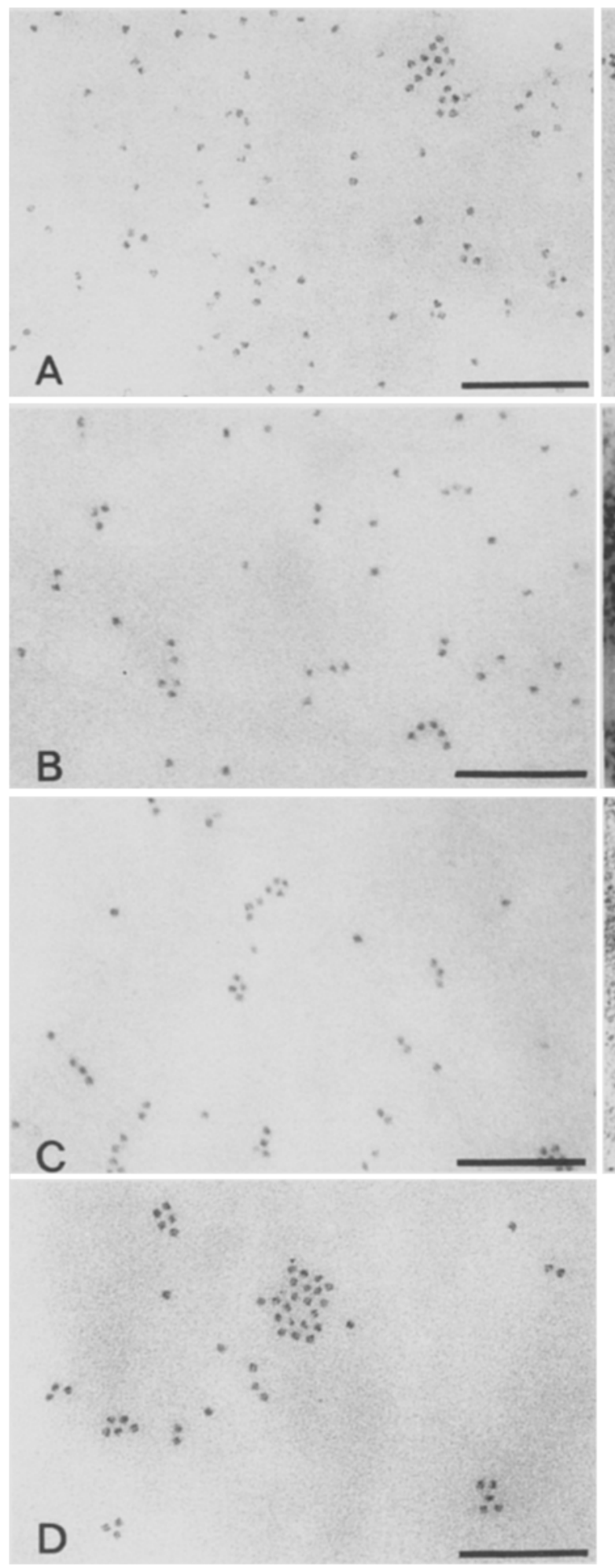

20-23 kDa, depending on the marker used. Immunoblotting with siderosomal products was not possible due to unavailability of material. Therefore we used additional siderosomal material from fresh livers for the Western blot (Fig. 7). SF shows many extra smaller and larger peptides along with the $20.5-\mathrm{kDa}$ peptide (43-67 $\mathrm{kDa}, 20-25 \mathrm{kDa}$ and $12 \mathrm{kDa})$. SIC contains the 20.5$\mathrm{kDa}$ peptide and a peptide of $18 \mathrm{kDa}$. Haemosiderin
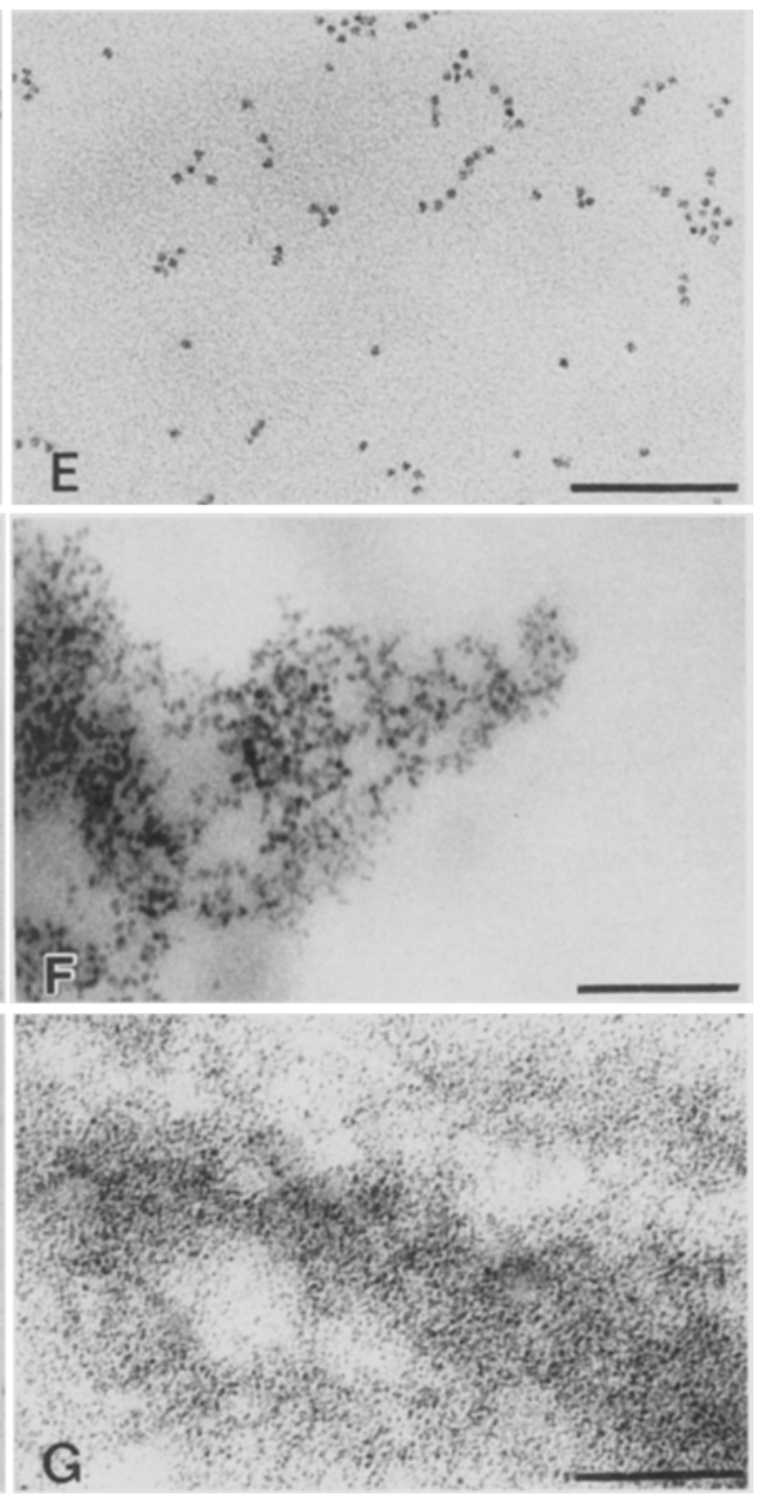

Fig. 3. ESI (zero-less) micrographs of CF (A), CLF (B), LF (C), LLF (D), SF (E), SIC (F) and $\mathrm{HS}(\mathbf{G})$. Bar represents $100 \mathrm{~nm}$

reacts only faintly. CF and LF from fresh liver were used as a reference.

\section{Discussion}

In a previous study (Ringeling et al. 1989) to determine the effect of dialysis on $\mathrm{Fe} / \mathrm{P}$ ratios of various rat liver 


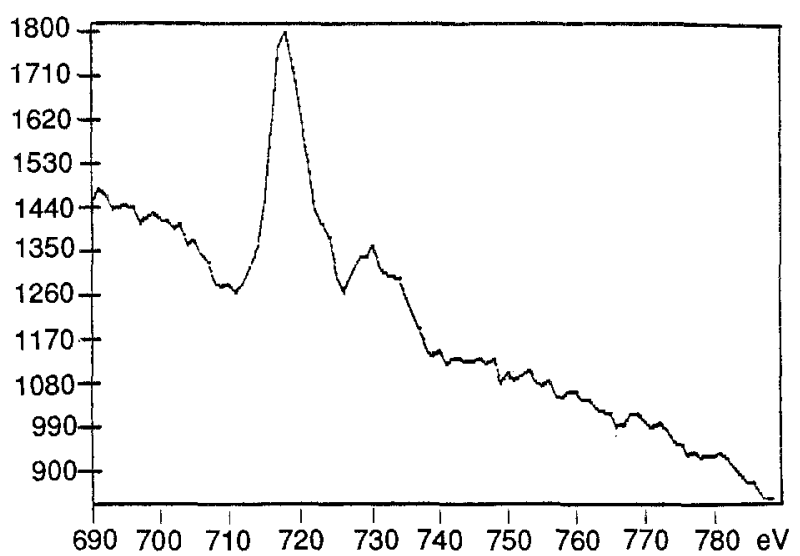

Fig. 4. EELS spectrum of SIC, with relative intensity on the $y$ axis and energy (in $\mathrm{eV}$ ) on the $x$ axis

Table 1. Diameters of the iron cores and $\mathrm{Fe} / \mathrm{P}$ ratios of all products

\begin{tabular}{lrccccc}
\hline $\begin{array}{l}\text { Fract- } \\
\text { ion }\end{array}$ & $n$ & $\begin{array}{l}\text { Diameter } \\
\text { (nm) }\end{array}$ & $P$ & $n$ & Fe/P & $P$ \\
\hline CLF & 692 & $6.1 \pm 0.6$ & & 10 & $5.5 \pm 1.7$ & \\
CF & 170 & $6.9 \pm 0.9$ & $*$ & 12 & $3.5 \pm 0.8$ & $*$ \\
LLF & 3074 & $6.7 \pm 0.8$ & $*$ & 10 & $4.9 \pm 1.1$ & $*$ \\
LF & 709 & $7.6 \pm 0.9$ & $*$ & 13 & $8.0 \pm 4.0$ & $*$ \\
SF & 544 & $7.2 \pm 0.9$ & $*$ & 13 & $10.6 \pm 3.6$ & n.s. \\
SIC & - & $<6$ & $*$ & 10 & $12.1 \pm 2.8$ & n.s. \\
HS & - & $<6$ & n.d. & 12 & $17.5 \pm 3.4$ & $*$ \\
\hline
\end{tabular}

Results are the average $\pm \mathrm{SD}$. ${ }^{*}$ represents $P<0.05$ determined by the student $t$-test; n.s. $=$ not significant; n.d. = not determined

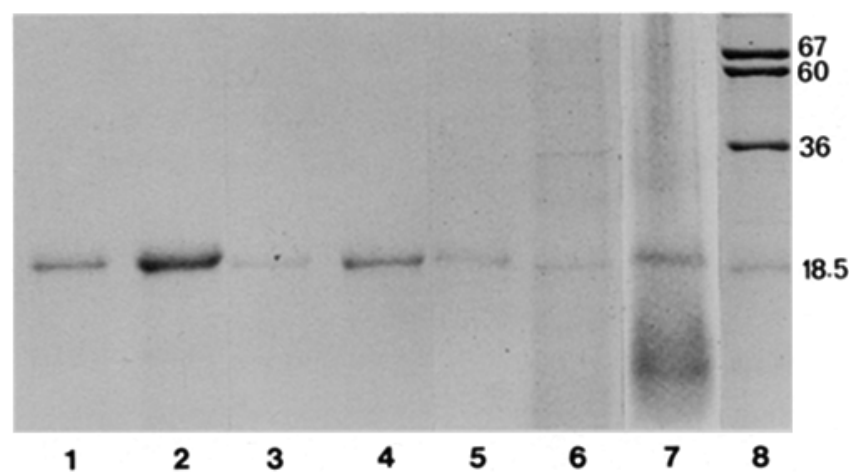

Fig. 5. SDS/PAGE of CF (1), CLF (2), LLF (3), LF (4), SF (5), SIC (6), HS (7), HMW Pharmacia (8)

ferritins, we obtained a cytosolic and a siderosomal ferritin fraction by Sepharose 6B chromatography. We mentioned that the main siderosomal fraction was very heterogeneous, containing in addition to ferritin large iron-deficient material. After chromatography over a Sepharose 4B column this fraction produced a fraction with an $\mathrm{Fe} / \mathrm{P}$ ratio of $8: 1$ (unpublished). Moreover, the cytosolic fraction as used in the previous study displayed lysosomal enzyme activity, indicating contami-

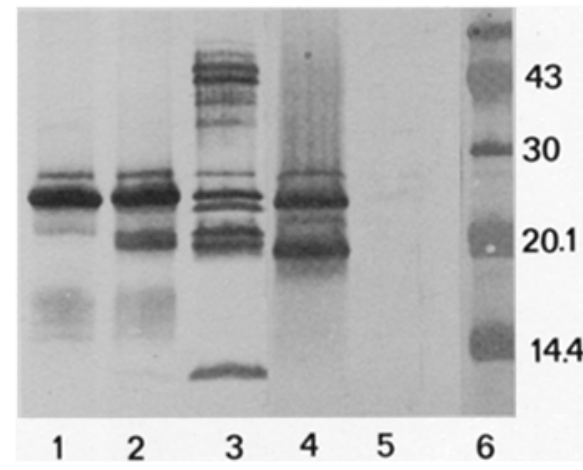

Fig. 6. Western blot after SDS/PAGE of LLF (1), LF (2), CLF (3), CF (4), low-molecular-mass material (5); LMW Pharmacia (6)

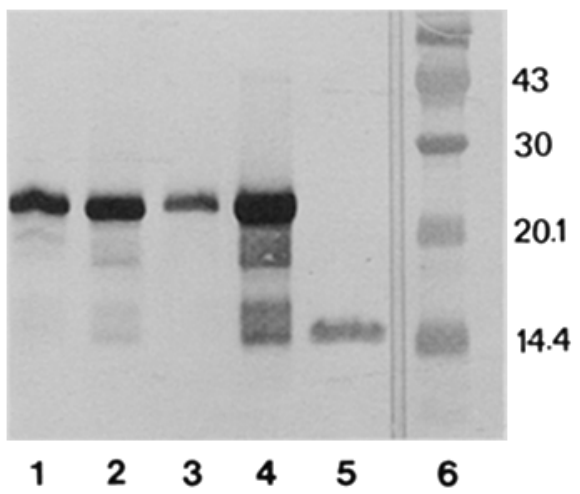

Fig. 7. Western blot after SDS/PAGE of additional material isolated from fresh livers. CF (1), LF (2), SF (3), SIC (4), HS (5) LMW Pharmacia (6)

nation with lysosomal material. Considering these data, we decided to switch to a more gentle fractionation technique (Richter 1984) using the total liver homogenate before starting experiments with parenchymal cells vs sinusoidal cells. This technique allowed us not only to obtain a relatively pure cytosolic fraction, but also to separate the lighter (mainly ferritin-containing) lysosomes from the heavily loaded (mainly haemosiderincontaining) siderosomes. In this way we obtained, all in one procedure, (a) a cytosolic fraction, (b) a lysosomal fraction, (c) a siderosomal fraction and (d) haemosiderin (Fig. 1). From these fractions all iron-containing compounds were isolated (Fig. 2) and compared with each other. The low-molecular-mass material, probably representing partly degraded ferritin, was left out of the comparison because it does not contain the $20.5-\mathrm{kDa}$ subunit but another subunit that requires further investigation.

Comparing the lysosomal products (LF and LLF, Fig. 2) with the cytosolic products (CF and CLF, Fig. 2) we see that they have much in common. The conclusion that the products from these cellular compartments are ferritins seems to be right, as they (a) react with anti(liver ferritin antibodies), (b) are soluble in water, (c) contain a $20.5-\mathrm{kDa}$ subunit reacting positively in the Western blot (Fig. 6), and (d) resemble ferritin morpho- 
logically (Fig. 3). However, the lysosomal products do differ from the cytosolic ferritins with respect to two parameters: iron-core size and $\mathrm{Fe} / \mathrm{P}$ ratio, both increased in the lysosomal ferritins (Table 1). Our morphometric data about the core size are in line with those from Iancu et al. (1987) who observed a similar difference in size between cytosolic and lysosomal ferritin in situ in enterocytes from the small intestine of carbonyl-iron-loaded rats.

Preliminary biochemical results indicate that the iron content of our ferritins increases in parallel to the increase in iron core diameter. This would mean that lysosomal ferritin is still capable of taking up iron inside the lysosome. However, our biochemical data result from only one experiment. Besides, ferritin concentrations are calculated without taking into account the possible differences in immunological reactivity between cytosolic and lysosomal ferritins. Yet, when we combine our morphometric data, i.e. an increase in diameter and an increase in $\mathrm{Fe} / \mathrm{P}$ ratio in the lysosomal ferritin, we must assume a (relative) increase in iron and/or a (relative) decrease in phosphorus. Protein analysis indicates that no changes occur to the protein coat after lysosomal uptake. Apparently, the first events that take place in the lysosomal compartment are the uptake and storage of ferritin without loss of its iron and without degradation of its mantle protein.

Comparing the siderosomal products with the lysosomal products, we see that they have less in common. Next to the siderosomal ferritin two other products are present. Unlike the siderosomal ferritin, these products, the siderosomal iron compound (SIC) and the haemosiderin, do not resemble ferritin greatly in that they are water-insoluble and that they do not react with specific anti-ferritin antibodies. It is not likely that the siderosomal iron compound is iron dextran, because intracellular iron dextran disappears from the liver over a two-week period following the iron-dextran injections (de Bakker 1983; Andrews et al. 1988b). All three siderosomal products differ from the lysosomal products in that their $\mathrm{Fe} / \mathrm{P}$ ratio is increased and the iron core diameter is smaller. Assuming that siderosomal ferritin originates from lysosomal ferritin, the increase in $\mathrm{Fe} / \mathrm{P}$ ratio with a simultaneous decrease in core diameter can only be explained by a heavy loss of phosphorus accompanied by or inducing a smaller loss of iron. This suggestion is supported by Treffry and Harrison (1978) who showed that phosphate is released more readily, and ahead of iron, from native ferritin. They suggested that much of the phosphate was located on core surface sites and therefore lost as surface iron is lost.

SDS/PAGE (Fig. 5) shows that all products are ferritin-related, as they all contain the $20.5-\mathrm{kDa}$ subunit. In the Western blot, however, other ferritin-related peptides are also visible. These peptides are not present in the cytosolic ferritin, faintly in the lysosomal ferritin, but they are numerous in the siderosomal ferritin. As is known from literature (Crichton 1969) iron stabilizes the protein shell. A loss of iron, therefore, could lead to destabilization of the ferritin protein shell. Another possibility is that, as soon as iron is lost from the core, the ferritin protein coat is degraded by an iron-catalysed Fenton reaction. This reaction is supposed to occur in the siderosomes and to be responsible for lipid peroxidation of the siderosomal membranes, causing a higher fragility of these membranes (Bacon and Britton 1990; Selden et al. 1980). Both possibilities could explain why in the Western blot the $20.5-\mathrm{kDa}$ subunit is found along with other peptides in the siderosomal products. Apparently, the siderosomal compartment is the place where the greatest changes to the ferritin molecule take place.

So, different processes take place in the lysosomes and in the siderosomes. The lysosomes function as a site where ferritin storage takes place, whereas the siderosomes function as a site of ferritin breakdown.

Acknowledgements. The authors wish to thank Miss L. W. J. Sorber and Mr M. J. Kroos for their skilled technical assistance and Miss L. P. C. Harkes for her preparation of the manuscript. We also thank Prof. P. M. Harrison for her critical review of the manuscript.

\section{References}

Andrews SC, Treffry A, Harrison PM (1987) Siderosomal ferritin. The missing link between ferritin and haemosiderin? Biochem J 245:439-446

Andrews SC, Brady MC, Treffry A, Williams JM, Mann S, Cleton MI, Bruijn de WC, Harrison PM (1988a) Studies on haemosiderin and ferritin from iron-loaded rat liver. Biol Metal 1:33 42

Andrews SC, Treffry A, Harrison PM (1988b) Studies on the subcellular processing of iron dextran by rat liver. Biochem Soc Trans 16:854-855

Bacon BR, Britton RS (1990) The pathology of hepatic iron overload: a free radical-mediated process? Hepatology 11:127137

de Bakker JM (1983) On the origin of peritoneal resident macrophages. PhD thesis, University of Leiden

Biemond P, van Eijk HG, Swaak AJG, Koster JF (1984) Iron mobilization from ferritin by superoxide derived from stimulated polymorphonuclear leucocytes. Possible mechanism in inflammation diseases. J Clin Invest 73:1576-1579

Brady MC, Lilley KS, Treffry A, Harrison PM, Hider RC, Taylor PD (1989) Release of iron from ferritin molecules and their iron cores by 3 -hydroxypyridonine chelators in vitro. $\mathrm{J}$ Inorg Biochem 35:9-22

Cleton MI, Frenkel EJ, de Bruijn WC, Marx JJM (1986) Determination of iron to phosphorus ratios of iron storage compounds in patients with iron overload: a chemical and electron probe $\mathrm{X}$-ray microanalysis. Hepatology $5: 848-851$

Cleton MI, Mostert LJ, Sorber CJW, de Jong AAW, de Jeu-Japars CMH, de Bruijn WC (1989) Effect of phlebotomy on the ferritin-iron content in the rat liver as determined morphometrically with the use of electron energy loss spectroscopy. Cell Tissue Res 256:601-605

Cooper PJ, Iancu TC, Ward RJ, Guttridge KM, Peters TJ (1988) Quantitative analysis of immunogold labelling for ferritin in liver from control and iron-overloaded rats. Histochem J 20:499-509

Crichton RR (1969) Studies on the structure of ferritin and apoferritin from horse spleen. I. Tryptic digestion of ferritin and apoferritin. Biochim Biophys Acta 194:34-42

de Duve C, Wattiaux R (1966) Functions of lysosomes. Annu Rev Physiol 28:435-492 
Fischbach FA, Gregory DW, Harrison PM, Hoy TG, Williams JM (1971) On the structure of hemosiderin and its relationship to ferritin. J Ultrastruct Res 37:495-503

Harris DC (1978) Iron exchange between ferritin and transferrin in vitro. Biochemistry 17:3071-3078

Harrison PM, Hoy TG, Macara IG, Hoare RJ (1974) Ferritin iron uptake and release. Structure-function relationships. Biochem J 143:445 451

Harrison PM, Ford GC, Rice DW, Smith JMA, Treffry A, White JL (1987) Structural and functional studies on ferritins. Biochem Soc Trans 15:744-748

Hezel UB, Bauer R (1987) Zeiss Information. MEM Oberkochen $5: 28-30$

Hoy TG, Jacobs A (1981) Ferritin polymers and the formation of haemosiderin. Br J Haematol 49:593-602

Hultcrantz R, Ahlberg J, Glaumann H (1984) Isolation of two lysosomal populations from iron-loaded rat liver with different iron concentration and proteolytic activity. Virchows Arch B Cell Pathol 47:55-65

Iancu TC, Lichterman L, Neustein HB (1978) Hepatic sinusoidal cells in iron overload. Ultrastructural observations. Israel $\mathbf{J}$ Med Sci 14:1191-1201

Iancu TC, Ward RJ, Peters TJ (1987) Ultrastructural observations in the carbonyl iron-fed rat, an animal model for haemochromatosis. Virchows Arch B Cell Pathol 53:208-217

Laemmli UK (1970) Cleavage of structural proteins during the assembly of the head of bacteriophage T4. Nature 227:680-685

Mancini G, Carbonara AO, Heremans JF (1965) Immunocytochemical quantitation of antigens by single radial immunodiffusion. Immunochemistry $2: 235-240$

Milsom DW, Rose FA, Dodgson KS (1972) The specific assay of arylsulphatase $\mathrm{C}$, a rat liver microscomal marker enzyme. Biochem J 128:331-336

Mostert LJ, Cleton MI, Bruijn de WC, Koster JF, Eijk van HG (1989) Studies on ferritin in rat liver and spleen during repeated phlebotomy. Int J Biochem 21:39-47

Ottensmeyer FP, Andrew JW (1980) High-resolution microanalysis of biological specimens by electron energy loss spectro- scopy and by electron spectroscopic imaging. $\mathbf{J}$ Ultrastruct Res $72: 336-348$

Penders TJ, de Rooij-Dijk HH, Leijnse B (1968) Rapid isolation of ferritin by means of ultracentrifugation. Biochim Biophys Acta 168:588-590

Richter GW (1978) The iron-loaded cell. The cytopathology of iron storage. Am J Pathol 91:362-404

Richter GW (1984) Studies of iron overload. Rat liver siderosome ferritin. Lab Invest 50:26-35

Richter GW (1986) Studies of iron overload. Lysosomal proteoly sis of rat liver ferritin. Pathol Res Pract 181:159-167

Rimbert JN, Dumas F, Kellershohn C, Girot R, Brissot P (1985) Mössbauer spectroscopy study of iron overloaded livers. Biochimie 67:663-668

Ringeling PL, Cleton MI, Kroos MJ, Sorber CWJ, de Bruijn WC, Harrison PM, van Eijk HG (1989) Lysosomal and cytosolic ferritins. A biochemical and electron-spectroscopic study. Biol Metals 2:114-121

Selden C, Owen M, Hopkins JMP, Peters TJ (1980) Studies on the concentration and intracellular localization of iron proteins in liver biopsy specimens from patients with iron overload with special reference to their role in lysosomal disruption. $\mathrm{Br} J$ Haematol 44:593-603

Sindram JW, Cleton MI (1986) The human liver in iron overload. $\mathrm{PhD}$ thesis, University of Utrecht

Theil EC (1987) Ferritin: structure, gene regulation and cellular functions in animals, plants and microorganisms. Annu Rev Biochem 56:289-315

Treffry A, Harrison PM (1978) Incorporation and release of inorganic phosphate in horse spleen ferritin. Biochem J 171:313320

Treffry A, Harrison PM, Cleton MI, Bruijn de WC, Mann S (1987) A note on the composition and propertis of the ferritin iron cores. J Inorg Biochem 31:1-6

Weir MP, Gibson JF, Peters TJ (1984) Biochemical studies on the isolation and characterization of human spleen haemosiderin. Biochem J 223:31-38

Wixom RL, Prutkin L, Munro HN (1980) Hemosiderin: nature, formation and significance. Int Rev Exp Pathol 22:193-224 